\title{
Applying Descriptivist Norms to Fantasy Translation
}

\author{
Birsanu Roxana, Lecturer, PhD \\ Romanian-American University, Romania
}

Doi:10.19044/esj.2020.v16n29p1 ～URL:http://dx.doi.org/10.19044/esj.2020.v16n29p1

\begin{abstract}
This paper focuses on the presence in Romania of J.R.R. Tolkien's The Hobbit or There and Back Again as an illustrative example of fantasy, or, more precisely, high fantasy in the Romanian literary system. The translation of fantasy as a component of children's literature requires compliance with a set of norms and conventions that reflect both the requirements of a particular target language and those connected with the specifics of this category of readers. Having G. Toury's classification of norms as a starting point, the investigation will attempt to detect the norms that informed translators' decisions, the extent to which these norms are an emanation of the time of translation production and whether the translators are consistent with the extratextual norms and their own textual strategies. From among Toury's norms, particular attention will be given to the initial ones, with the goal of identifying the preferred orientation of the target texts either towards acceptability or towards adequacy. The investigation will rely mainly on structures and textual units extracted from the target productions, since the main objective is to unveil repeated patterns of translation behavior likely to suggest mechanisms of norm generation.
\end{abstract}

Keywords: Translation norms, descriptive translation studies, adequacy, acceptability, naturalization

\section{Introduction}

The translation of a literary text in a target culture is never the result of an accident, nor does it occur in a contextual void. It is produced in a very well-defined time frame, following various classes of requirements and needs which range from reader expectations and demand for a certain literary genre to the need of a literary system to rejuvenate or enrich its forms of expression through the import of new genres and writing styles.

Translation production is contingent to a set of conventions and standards that may even reach the status of rules that are manifest in the target culture and that guide the reception of the translated text in certain directions. In pursuing this activity, translators need to be aware of the existence of such 
norms and act upon them, if their concern is to produce a text that is unanimously acceptable in the target culture, or go against them, undertaking at the same time the consequences of their choice. There are, however, situations and contexts in which the translator does not have this option, mainly in dictatorial regimes where norms are very strictly regulated and not to be flouted. Likewise, there are literary genres with quite inflexible rules that are imposed by their very structure and/or the target readership envisaged.

The translation of children's literature is such a type of fiction in which translators have to pay heed to various factors in order for their target versions to be acceptable to and accepted by their young readers. In this case, when translation conventions or rules are not under the form of prescriptive statements emanating from the translation practice, they can only be reconstructed following an investigation of target text structures and repeated translation behavior (Shuttleworth and Cowie, 1997: 114), which reveal the existence of such norms.

Relying on the contentions of descriptivist scholar Gideon Toury on translation norms, this paper sets to investigate the norms that operate in the Romanian translation of high fantasy literature, with a particular focus on two Romanian versions of Tolkien's The Hobbit or There and Back Again. Given the fact that there is a twenty-year time span between the two target productions, the analysis will strive to detect the extent to which they are the products of their time, including through their (in)compliance with the translation norms prevalent at the time. As the purpose is to detect norms that govern the production of target language texts, the units of analysis will mainly pertain to the two target texts under discussion.

\section{Observations on fantasy literature}

For all their charm and appeal to children and adults alike - or probably because of the double public they address - fantasy works are a highly challenging task for any translator. This is accounted for by a variety of reasons and all have to do with the specifics of this form of fiction and the requirements that have to be met when transferring it from one source language/culture into a target one.

Since The Hobbit is an illustrative work of high fantasy, this paper will focus on this subgenre of fantasy fiction. High fantasy started its career at the beginning of the twentieth century due to names such as J.R.R. Tolkien, C.S. Lewis or Michael Ende, who signed some of its most representative titles. The history of the genre takes its roots in the rich mythology of various European civilizations (Greek, Roman, British, Germanic etc.), fairy tales or the romance stories that dominated the middle ages. In this light, an inspired definition is provided by Gates et al.: "Fantasy is imaginative fiction that allows us to explore major life mysteries without being limited by size, time 
or space. More specifically, fantasy literature, like all other forms of myth, springs from the human need to understand the struggle of good versus evil. All of ancient mythology reflects the give and take of this struggle; still make and use myth, through fantasy literature, in order to deal with it. Herein lies the por of fantasy and myth, because the struggle never ends" (2003: 2). This probably partially accounts for the fact that fantasy literature has such a large number of fans.

There are a number of elements that come into the making of any piece of fantasy and almost every one of them may represent a touchstone for translators. One such salient feature of fantasy writings is the setting, which is a character in itself. In high fantasy, it is a realm called a second world, a universe that differs from the primary one through its rules and conventions. Tolkien's Middle Earth of Lewis's Narnia are among the best-known examples. In close connection with the extraordinary nature of the setting is the presence of magic, another essential ingredient of high fantasy. Characters and events rely heavily on magic in order to fulfill their roles. Obviously, if there is magic, there must be supernatural beings, from wizards, elves and werewolves to talking animals and plants.

As the premise of high fantasy is the millennium-old antagonism good - evil, fantasy writings are also provided with villains who are not normally easily defeated and who are also in possession of magic skills. As good and evil forces are supposed to face each other directly at some point, a great confrontation, usually under the form of an epic battle, is another defining component of high fantasy. Last, but not least, there is language. Similar to the setting, language can be a character in its own right. Sometimes the heroes speak an invented one - as are the languages created by Tolkien - other times it is merely a peculiar use of an existing language, customarily in an elevated register. Idiolects are particularly significant, because oftentimes they are key for character development.

The genre has long been considered 'minor' by the literary establishment, despite the growing interest of the reading public and the obvious aesthetic values of the works. Therefore, fantasy researchers have strived to summarize a number of features that recommend it as a valuable genre, worthy of academic investigation. Gates et al. call these "qualities" and mention six of them which are relevant not only for the intrinsic worth of the works themselves, but also in the broader context of literary studies, history or psychology. Thus, one of these qualities is the imitative nature of fantasy, as it basically relies on aspects of real life and universal imagination. However, it is also original, since it reinterprets these spiritual artefacts and turns them into new material.

Another quality resides in the power of fantasy to preserve the past precisely through the revival and rejuvenation of ancient material. At the same 
time, "fantasy can be an effective agency for change, renewal and liberation when, refusing to be bound to the present and past, the visible and physical, and the traditional and established, it plays with what might be, makes what does not yet exist and elaborates any number of possible futures" (2003: 6). Yet another positive feature of fantasy is that it enhances religious beliefs through its refusal to accept limitations of whatever order and its aspiration towards a transcendent universe. Finally, the manifested preference for hypothetical and seemingly impossible situations suggests that fantasy would be a subversive force for the conventionality and surface respectability of reality.

Despite the fact that fantasy is mainly deemed a genre addressing children and young adults, its appeal expands beyond the world of childhood and has charmed grown-ups as well. It is true that adults, more than children, have not been drawn towards the world of fantasy only through reading, but also due to a reconsideration of it as a transmedia genre which crosses various forms of artistic manifestation, from cinema adaptations and television series to comic books, illustrations, video games or dedicated festivals (Heller, 2014). That is why, in the translation of every piece of fantasy literature, one of the aspects to be taken into account by the translator is the mixed range of readers s/he addresses, i.e. both children and adults.

\section{Background information on The Hobbit}

J.R.R. Tolkien is by now, next to the great classics of his country, one of the iconic names of $20^{\text {th }}$ century British literature. His works have been translated into over thirty languages and his fame is still growing, despite the fact that he would most likely not be highly pleased with this success. Actually, the celebrity that the publication of The Hobbit or There and Back Again (1937) brought him surprised him, but not in positively. However, Bilbo Baggins's adventures have proven to be an enduring story that has enchanted generations of children and adults alike.

This heroic-ethical fantasy (Gates et al., 2003: 111) is representative for the genre to which it belongs. The hobbit Bilbo Baggins sets off on a journey as assistant to a group of dwarves to reclaim an ancient dwarfish treasure now captured by Smaug, the dragon. The outcome of this quest is not only the recovery of the much-wanted treasure, but also a discovery of the strengths and noble features of character that lie dormant in the heart of the little hobbit. In the process, he becomes more mature and responsible and more appreciative of the values of true friendship. The motif of personal development and enlightening is completed by a darker one, that of warfare, as the story ends in an epic confrontation, the Battle of Five Armies, which features all the races that gradually appear in the novel, as almost each chapter 
introduces a special race of the surreal creatures that populate Tolkien's Middle Earth.

Despite the huge success that The Hobbit enjoyed abroad, in Romania it was translated for the first time in 1975. The translator, Catinca Ralea, was a very active presence in the Romanian cultural life as a translator, journalist and producer of radio and TV shows. The publishing house that issued her translation was Minerva, one of the best-known at the time, in its prestigious collection, Biblioteca pentru toți copiii, a spin-off of the collection dedicated to adult readers, Biblioteca pentru toți. As The Hobbit had gained its place as a must-read in children's literature and its worldwide acclaim was growing, the interest in the retranslation of this work became more visible in Romania as well. So it is that it benefits from three more translations: one in 1995 (signed by Junona Tutunea, at Elit Publishing House), and two in 2007 (one signed by Dan Slusanschi and the other by Irina Horea, at RAO Publishing House, which actually has the ownership rights for all Romanian translations of Tolkien's works). In this paper the focus will be on the 1975 and the 1995 versions, with a twenty-year span between them, as they suit best the purposes of this analysis.

\section{Norms in translation}

By and large, fantasy literature is considered to be part of children's literature and, as such, in the transfer to the target language, translators mainly apply strategies and techniques which are normally used in the translation of this form of literature. But, with fantasy writings, almost any element of the structure may turn into a translation stumble block. On the one hand, there is the particular category of readers envisaged, with their special requirements in terms of richness of life experience (or, rather, lack thereof), previous readings and familiarity with the genre, assumed degree of relatability with the characters and their life and adventures or expectations built based on exposure to the film or cartoons first (as may be the case with the movie adaptations of The Hobbit or the Narnia chronicles). On the other hand, there are the intrinsic challenges of the genre which force translators to demonstrate the force of their own imagination in the rendition of invented languages or loaded proper names, but also in the accurate choice of register or in the use of the proper techniques for culture-specific items.

The process of translation is not an act that unfolds in isolation; it is, particularly nowadays, with the unparalleled movement of persons across borders, an essential coordinate of communication. As an element of social and cultural cohesion, in order to fulfill its role of a communication tool, it has to abide by a set of rules or norms that govern this activity in the target language/culture. The process and, in the end, the outcome of the translation activity are not merely the result of translator idiosyncrasies; there are also 
other factors that impact it such as publishers, editors, a translation tradition that has created certain expectations with readers, or even prescriptions from professional associations that regulate this activity.

Norms have had distinct approaches in Translation Studies research as conventions or rules even, but this study will consider the concept of "norms" as advanced by translation scholar Gideon Toury. According to the Israeli professor, what is essential with this concept is that norms are imposed by the macrotextual context and that failure to comply with them entails some sort of negative consequences. Toury follows the sociologic approach to norms: "Norms are the key concept and focal point in any attempt to account for the social relevance of activities, because their existence, and the wide range of situations they apply to (...) are the main factors ensuring the establishment and retention of social order. This holds for cultures, too, or for any of the systems constituting them, which are, after all, social institutions ipso facto" (1995: 55). By applying this concept of norms to translation, he highlights the social function of the translation activity and its relevance in the regulation of life in a given language community.

Toury contends that the application of norms starts even before the translation process per se, in the stage of translation initiation/commissioning. His taxonomy comprises three classes of norms. The preliminary ones reflect basically the translation policy (which governs the decision related to the selection of texts to be translated in terms of authors, text types, source literature etc.) and directness of translation - whether the target text is produced following the source text or through the mediation of another translation. Initial norms mirror the orientation of the translation towards adequacy - in which the translator follows closely the textual and linguistic norms of the source text, producing an adequate translation - or acceptability, when the translator gives prominence to the conventions and standards of the target system. However, he claims that no translation is fully adequate or fully acceptable and that, ideally, the translation should strive to strike a balance between the two extremes.

Finally, operational norms deal with the actual strategies employed during the translation process. Matricial norms refer to the very matrix of the text, more precisely the target language material, its place in the target text and textual segmentation, whereas textual-linguistic ones dictate which target linguistic material will replace the source one.

In this paper, the focus is on the initial norms, with their two extremes of translation - adequacy vs acceptability. Considering that there is no absolute adequate or acceptable translation, the above-mentioned norms will be applied to two versions of the Romanian Hobbits in an attempt to detect whether the translators were more concerned with acceptability or adequacy. As already mentioned, the aim is to detect the translation techniques and 
strategies that might suggest the overall orientation of the target texts under analysis in respect of compliance with/flouting of norms.

\section{Norms applying to the translation of Tolkien's The Hobbit \\ Preliminary norms}

It should be mentioned from the onset that for Romanian there are no specific prescriptive statements on translation norms made by professional bodies. They have to be inferred from recurrent practices and a tradition in the translation of certain text types and genres. As it happens, Toury suggests regularity as a guiding principle in the identification and reconstruction of translation norms: "Inasmuch as a norm is really active and effective, one can therefore distinguish regularity of behaviour in recurrent situations of the same type, which would render regularities a main source for any study of norms" (1955: 55). In other words, the more frequent a certain linguistic phenomenon, the more valid the assumption that it is an active norm. The analysis will rely on target text units as tools to reconstruct the principles of translation behavior along the lines of external norms or compliance with the translator's own agenda.

In the particular case of the Romanian versions of The Hobbit, consideration of the preliminary norms - which are extratextual - reveals the position this text occupies in the Romanian literary system as a representative of its specific literary genre. As norms are a reflection of the status of society at a given moment in time, proper contextualization is paramount, as it dictates the adoption of certain norms and informs translation decisions. Ralea's version appeared in 1975, during the communist period. The communist regime ruled in Romania for around forty-five years, during which translation policies underwent various fluctuations that reflected the Party ideology, the central concerns with propaganda and the dissemination of communist principles. Censorship was the supreme mechanism that ensured compliance of the local literary system (both translations and the production of original works) with Party rules and it was highly effective in purging it of any 'harmful' foreign influences, making it a point of high priority to "fight against the condemnation of the decadent, 'rotten' bourgeois culture that cultivated exploitation and cosmopolitanism" (Pâcleanu, 2018: 36). This was particularly valid up until the sixties, which marked the beginning of a so-called period of liberalization. While during the previous periods translations were made particularly from communist literatures, with a marked preference for the Soviet one - an extremely powerful tool of manipulation and propaganda, between the sixties and the eighties the translation activity reached its peak. The greatest winner was Anglo-American literature, much neglected, even marginalized, during the previous epochs. Relevant for the above-mentioned period was also the fact that, at long last, contemporary works were allowed 
for translation, since only classics had been rendered into Romanian up until a few years before. The scope of translated works was so large, that it almost equaled original works.

A very important document which can be deemed a scan of the approach to and context of translation during the period under discussion is represented by the interventions of the 1981 National Conference on Translation and World Literature, which was attended by the most celebrated names in Romanian translation. On the topic of source texts, Romul Munteanu, one of the speakers, argued that they had to be compatible with the reading expectations of Romanian readers, their literary tastes and the synchronization with the realities of world literature. As censorship was still very much active, the main translation orientation continued to be the naturalization of source texts and the production of fluent translations that would take the texts as close to the readers as possible, not run counter the dominant ideology and not introduce new, subversive ideas.

In this light, Ralea had the great merit of introducing Romanian readers to a literary genre that was inexistent in Romanian literature - fantasy, and to the work of Tolkien, who was already, by the seventies, an acclaimed name in British literature. At the time there was not even talk of 'fantasy' and that is why, in the Foreword, she contextualized the text by designating it as 'fantastic', thus inscribing it in the tradition of the Romanian folk tale, with which young readers were all too familiar.

Junona Tutunea's translation was produced twenty years later, on the background of a completely different landscape of translation into Romanian. The communist regime was overthrown in 1989. The period immediately following was dominated by a series of liberties that had a profound impact on the activity of translation. While during the communist era there was a limited number of publishing houses, after 1989 a plethora of new, private publishing houses appeared. Their activity relied heavily on the translation of mass literature, with preference for science fiction, romance and detective novels. Readers finally had access to these genres, mostly frowned upon during the previous period, and the publishing houses were all too eager to deliver. Under the pressure of the demand and drawn by the lure of rapid financial gains, they printed translations that were performed at a fast pace, with little regard for translation faithfulness or ethical norms. The massive interest in science fiction - mainly addressing a grown and teen readership also opened the door to fantasy, which was targeted at children. Similarly, the general approach to the translation of children's literature still followed the orientation of naturalization, with little concern for exposing young readers to the experience of the Other, of the foreign; this time, the purpose of fluency was not to comply with ideological constraints, but to make the text relatable to target readers. This is the extratextual context that surrounds the 1995 
publication of Tutunea's Povestea unui hobbit. The analysis of operational norms will reveal to which extent her approach reflects the extratextual context of translation production.

\section{Operational norms}

Toury argues that operational norms "affect the matrix of the text - i.e. the modes of distributing linguistic material in it - as well as the textual makeup and verbal formulation as such. They thus govern - directly or indirectly the relationships as well that would obtain between the target and source texts; i.e., what is more likely to remain invariant under transformation and what will change" (1995: 58). Operational norms cover thus translation decisions that affect the replacing and replaced structures respectively in terms of lexis, syntax or semantics and envisage in particular strategies such as omissions, additions, compensations or text segmentation techniques. Of particular relevance are the textual-linguistic norms, which "govern the selection of material to formulate the target text in, or replace the original textual and linguistic material with. Textual-linguistic norms may either be general, and hence apply to translation qua translation, or particular, in which case they would pertain to a particular text-type or/or mode of translation" (ibid., 59).

In the two analyzed target texts, compliance with the norm of naturalization, although driven by distinct motivations, is visible from the title. The Hobbit or There and Back Again is rendered by Ralea as O poveste cu un hobbit and by Tutunea as Povestea unui hobbit. In both versions the title is incomplete, the subtitle being completely removed in the target texts. By using the noun 'poveste', the two translators explicitly indicate the category of readers they address, i.e. children, and as specified above, they include the novel in the tradition of folk tales with the aim of inciting readers' imagination and drawing them to the text, creating at the same time expectations in terms of plot, character development or style. The addition of the noun 'poveste', inexistent in the source text, is completed by another manipulation of the original title through the use of the indefinite article "un", the equivalent of the English "a/an". But the initial title contains, on the contrary, the definite article, "the", which is meant to indicate that the character of this story is no ordinary hobbit, but one who distinguishes himself from all the others through his spirit of adventure, his feats and personality traits. By resorting to a replacement of the definite article with the indefinite one, the translators annihilated the uniqueness of the character and moved the focus on the idea of adventures, which is what you normally find in a 'poveste'.

The issue of neologisms and archaisms in the two target texts is of particular relevance from the perspective of particular operational norms, as they bear a special significance for the construction of fantasy literature. In fantasy in general and in high fantasy in particular, the time setting is 
immemorial, there is not a well-defined time frame. And yet, when they decided to embed the text in the local folk tale heritage, the Romanian translators also set the plot on the background of an atemporal frame, but a Romanian, archaic one, which automatically dictates an overflow of archaisms. Nevertheless, the source text does not display an overabundance of archaisms; hence, this translation technique is a departure from the intention of the author.

In Tutunea's case, archaizing is the feature that stands out in her translation, to be found at every textual level, from character idiolect to lexical choices in descriptions and dynamic scenes.

ST: The dwarves and Bilbo shouted and cheered. The rage of the wolves was terrible to see, and the commotion they made filled all the forest. Wolves are afraid of fire at all times, but this was a most horrible and uncanny fire.

TT: Piticii și Bilbo dădură chiote de bucurie. Lupii se înfuriaseră la culme, iar larma pe care o stârniseră răsuna până dincolo de pădure. Dintotdeauna, lupilor le-a fost frică de foc, dar cel care se abătuse atunci asupra lor era cumplit și iscat prin putere vrăjitorească.

As can be noticed in the comparison with the source fragment, the language in the source text is neutral, yet powerful in visual imagery. Conversely, the choice of target language vocabulary such as 'chiote', 'larmă', 'iscat', 'putere vrăjitorească', imprints the text with a fairy tale-like tone. Moreover, there are two additions that could have easily been avoided. 'This' is translated as 'care se abătuse atunci asupra lor' and 'uncanny' is interpreted as 'putere vrăjitorească'. The ST merely alludes to Gandalf's intervention, whereas the TT makes it explicit to the readers.

The translator's preference for the archaic is visible in the selection of replacing structures that cover various parts of speech:

- nouns: 'pădureni', 'fârtați', ‘străjeri', 'mai-marele', ‘bidiviu', 'merinde', 'veșminte';

- verbs: ‘a împresura', ‘a se socoti', ‘a se veseli', ‘a nădăjdui', ‘a izbuti'; - adverbials: 'pasămite', 'defel', 'îndărăt', 'cătinel'.

In compliance with this tendency, verbal formulations or the particular selection of idioms remind of a fairy tale atmosphere: 'cât e ziulica de lungă', 'fie-ți milă', 'se crapă de ziuă', 'au bătut cale lungă', 'încremenise de spaimă' .

While Tutunea's translation displays a high level of intratextual coherence in respect of the elements mentioned above, a comparison in this respect with Ralea's version reveals certain inconsistencies. Steiner argues that the risk with the archaic orientation is that the translator will eventually produce a hybrid text, since it is quite improbable to be able and maintain an 
older usage of language throughout the entire text (1992: 360). This holds true for Ralea's text. Whereas she does not rely as heavily as Tutunea on archaisms, given the overall fairy tale orientation of her text, it would be inevitable not to resort to them. Hover, when the text displays formulations such as 'cazați', 'moștenitori legali', 'efracțiune' or 'decepționat', they feel anachronic in a text that is essentially set in a distant, archaic past.

The translation of proper names also deserves some consideration, as they represent a special category in fantasy writings. In fantasies, space is an invented construct, a scene inhabited by fantastic creatures pertaining to races which are sometimes of mythic extraction, while other times are products of the author's imagination. Consequently, proper names, regardless of whether they are toponyms or anthroponyms, are all carriers of meaning. As such, they require translation in the target language; failure to provide them with target equivalents entails loss of meaning and deprives the text of its intention and aesthetic effects.

The provision of target language equivalents for proper names through various strategies (spelling adaptation, phonetic adaptation, calque etc.) is a universal norm in the translation of fantasy in all languages. The Romanian translations followed it closely and consistently, with few exceptions. The translators did so because they rightly grasped the significance of semantically loaded names, but also as an expression of their overall naturalizing approach: 'Necromancer' - 'Necromantul' (Ralea), 'Solomonarul' (Tutunea); 'Elvenking' - 'Regele ielelor' (Ralea), 'Regele duhurilor pădurii' (Tutunea); 'Lonely Mountain' - 'Muntele Singuratic' (Ralea), 'Muntele însingurat' (Tutunea); 'Mirk Wood' - 'Pădurea întunecată' (Ralea), 'Padurea de nepătruns' (Tutunea). What differentiates the replacing elements in the two target texts are the translators' own creativity and interpretation of the source variants, some of them more poetic and inspired than others, thus producing distinct stylistic effects. Nevertheless, the norm is consistently complied with throughout, with obvious benefits for the target readership.

\section{Initial norms}

Initial norms are approached after the operational ones because it is considered that target text orientation towards adequacy or acceptability can be inferred from the translation strategies and decisions that become relevant following a closer study of various textual units. The analysis revealed that both translations follow the naturalizing path, which is visible from the very onset, when they inscribe the text in a certain literary tradition of the target culture. The strategies opted for in translation highlight the concern for acceptance of the text in the target culture through the replacement of source text structures with units that create a familiar setting for target readers. 
Tutunea's approach, through the constant interventions in lexis and syntax, the massive use of additions and archaisms, reveals an effort to make the text sound as an original to the point of suggesting a rewriting of the source text. Her concern for producing an acceptable text seems to outweigh the responsibility to find a balance between adequacy and acceptability, at points even ignoring auctorial intentions in respect of plot, stylistic effect or textual organization (there are numerous instances in which longer source paragraphs or phrases are split into shorter ones or even turned into new paragraphs).

On the other hand, Ralea's translation, although with a similar overall orientation, manages to maintain the balance between acceptability and adequacy. She followed the source text closely and resorted to naturalizing (and thus, acceptable) strategies only in instances required by the rule of consistency with the folk tale literary genre. This is supported, for example, by the translation of 'dragons' as the Romanian 'zmei', or 'elves' as 'iele'. Nevertheless, under the preliminary norm, her version displays a clear preference for adequacy in one major aspect: through the decision to translate this particular piece of writing signed by this particular author, her version is responsible for the introduction of a new genre, namely high fantasy, in the Romanian literary system. And this, by itself, balances the dominant preoccupation with acceptability that is evident in her translation decisions and consistency with textual norms.

\section{Conclusion}

Source and target text relationships are subject to a plethora of variables and occupy a continuum of rules and conventions that differ across cultural spaces, but also time periods, even within the same culture. As a normbased activity, translation operates within the confines of what is acceptable (linguistic, cultural, social) behavior in a certain language community. Obviously, the translator has the option to work along the line of these conventions, thus producing an acceptable target text, or running counter them, giving priority to the conventions that govern the production of the source text and thus building a text that is closer to the adequacy pole.

The exploration of two Romanian versions of Tolkien's The Hobbit revealed that Toury's classes of norms are intertwined and interdependent. Ralea's version is intriguing as, in some respects, it presents itself as a product of its time, which complies with the standards and expectations of its epoch, but it also goes beyond it, in an attempt to enrich the then existing literary framework. Tutunea's translation seems to be a reflection of the translator's agenda and interpretation of the source text, verging on extreme rewriting, with the outcome of producing a Romanian text marked by a high level of acceptability. However, her text has the merit of consistently pursuing 
strategies that ensure intratextual coherence with respect to syntax, semantics and textual organization.

\section{References:}

1. The Hobbit or There and Back Again. London: HarperCollins Publishers, 1995

2. O poveste cu un hobbit, translation by Catinca Ralea, poems translated by Leon Levițchi, București, Editura Ion Creangă, 1975.

3. Povestea unui hobbit, translation by Junona Tutunea, Ploiești, Editura Elit, 1995.

4. Gates, P., Steffel, S.S. \& Moldon, F.J. (2003). Fantasy Literature for Children and Young Adults. Lanham: Scarecrow Press.

5. Heller, E. (2014). When Fantasy Becomes a Real Issue: On Local and Global Aspects of Literary Translation/Adaptation, Subtitling and Dubbing Films for the Young. In Dror Abend David (ed.), Media and Translation: An Interdisciplinary Approach (pp. 173-195). New York \& London: Bloomsbury Publishing.

6. Pâcleanu, A. (2018). Not Only Taboo: Translating 'the Controversial' Before, During and After Communism. Cluj-Napoca: Casa Cărții de Știință.

7. Shuttleworth, M., and M. Cowie. (1997). Dictionary of Translation Studies. Manchester: St. Jerome Publishing.

8. Steiner, G. (1992). After Babel. Oxford \& New York: Oxford University Press.

9. Toury, G. (1995). Descriptive Translation Studies and Beyond. Amsterdam \& Philadelphia: John Benjamins Publishing Company. 